\title{
Comparison of two treatments for coxarthrosis: local hyperthermia versus radio electric asymmetrical brain stimulation
}

\section{Alessandro Castagna' \\ Salvatore Rinaldi ${ }^{1,2}$ \\ Vania Fontani' \\ Piero Mannu' \\ Matteo Lotti Margotti'}

'Rinaldi Fontani Institute, Department of Neuro Psycho Physio Pathology,

${ }^{2}$ Medical School of Occupational

Medicine, University of Florence,

Florence, Italy
Correspondence: Salvatore Rinaldi Rinaldi Fontani Institute, Viale Belfiore 43, Florence 50I44, Italy

Tel +3905 5290307

Fax +3905 5290399

Email srinaldi@irf.it
This article was published in the following Dove Press journal:

Clinical Interventions in Aging

22 July $201 \mathrm{I}$

Number of times this article has been viewed

Background: It is well known that psychological components are very important in the aging process and may also manifest in psychogenic movement disorders, such as coxarthrosis. This study analyzed the medical records of two similar groups of patients with coxarthrosis $(n=15$ in each) who were treated in two different clinics for rehabilitation therapy.

Methods: Patients in Group A were treated with a course of traditional physiotherapy, including sessions of local hyperthermia. Group B patients were treated with only a course of radioelectric asymmetrical brain stimulation (REAC) to improve their motor behavior.

Results: Group A showed a significant decrease in symptoms of pain and stiffness, and an insignificant improvement in range of motion and muscle bulk. A single patient in this group developed worsened symptoms, and pain did not resolve completely in any patient. The patients in Group B had significantly decreased levels of pain and stiffness, and a significant improvement in range of motion and muscle bulk. No patients worsened in Group B, and the pain resolved completely in one patient.

Conclusion: Both treatments were shown to be tolerable and safe. Patients who underwent REAC treatment appeared to have slightly better outcomes, with an appreciable improvement in both their physical and mental states. These aspects are particularly important in the elderly, in whom functional limitation is often associated with or exacerbated by a psychogenic component.

Keywords: coxarthrosis, anti-aging, motor behavior, radioelectric asymmetric brain stimulation

\section{Introduction}

In anti-aging medicine, as in various specialties of medicine, the symptoms of disease and disability often reflect the consequences of attempts of the nervous system to adapt to an insult by remodeling synaptic plasticity, which often results in adaptive responses that are not positive for health. ${ }^{1-3}$ The consequent adaptive responses may also be maladaptive, ${ }^{4}$ which can contribute to functional disability affecting motor control and posture. It is well known that psychological factors may manifest physically as psychogenic movement disorders, ${ }^{5-9}$ which may also have consequences at both the muscle and joint levels. ${ }^{10-15}$ This emotional component of movement disorders is often the basis for joint problems that occur in aging, and can be linked to inadequate coping reactions ${ }^{16,17}$ and environmental stress. ${ }^{18-20}$ The psychological component is often unknown to both the patient and the medical team, and therefore can be responsible for the limited effectiveness of physiotherapy. Recent work has focused on the development of various techniques for brain stimulation that can be used to improve 
motor and cognitive functions. ${ }^{21-24}$ Coxarthrosis is a disease affecting the hips. The pain is felt deeply in the middle of the groin. Initially it appears on movement of the joint, and later at rest. The pain radiates along the thigh and is located quite clearly in the knee. One treatment is classical physiotherapy with local hyperthermia, and another is radioelectric asymmetric brain stimulation (REAC), which aims to enhance motor and cognitive function. We investigated the use of these two techniques for the treatment of pain and functional impairment in elderly patients with coxarthrosis.

\section{Materials and methods}

This randomized retrospective study analyzed data in the medical records of two groups of patients with coxarthrosis attending two different clinics for rehabilitation therapy. The data were collected by a researcher who was not involved in the analysis or interpretation of the study data. Information recorded included the age, duration of symptoms, severity, and sociocultural background of each patient, which were matched between the treatment groups. Each patient was ranked by the Kellgren-Lawrence classification for arthrosis, as follows: $0=$ normal, 1 = questionable diagnosis, $2=$ incipient or mild arthrosis (slight narrowing of the joint space), $3=$ moderate arthrosis (distinct narrowing of the joint, bone cysts and sclerosis) and $4=$ severe arthrosis (severe structural disorder of the joint).

\section{Subjects}

Group A included 15 patients (10 females and five males, mean age, $61.46 \pm 7.57$ years) suffering from coxarthrosis (Kellgren-Lawrence classification grade $2[n=7]$ and grade $3[\mathrm{n}=8])$ and treated in a physiotherapy clinic. Group B included 15 patients (13 females and 2 males, mean age, $69.33 \pm 9.85$ years, Kellgren-Lawrence classification grade $2[\mathrm{n}=8]$ and grade $3[\mathrm{n}=7]$ ) who were treated in a clinic for stress-related disorders.

Despite the difference in mean age between the treatment groups, the clinical picture was similar (Table 1). In both groups the preliminary (T0) and the final (T1) clinical evaluation of patients was performed by different physiatrists and orthopedic specialists for each clinic. Physiatrists and orthopedic specialists, although belonging to different clinical disciplines, had similar professional skills.

\section{Measurements}

Pain was assessed by a paper-and-pencil visual analog scale measure. Range of motion in terms of active flexion of the hip, and knee flexion and extension (Figures 1 and 2), was
Table I Demographic variables

\begin{tabular}{lll}
\hline & Group A & Group B \\
\hline Patients & 15 & 15 \\
Female & 10 & 13 \\
Male & 5 & 2 \\
Age (years) & $75-49$ & $83-41$ \\
Mean age (years) & $61.46 \pm 7.57$ & $69.33 \pm 9.85$ \\
Kellgren-Lawrence & Level $2(\mathrm{n}=7)$ & Level $2(\mathrm{n}=8)$ \\
classification & Level $3(\mathrm{n}=8)$ & Level $3(\mathrm{n}=7)$ \\
Pain & $15(100 \%)$ & $15(100 \%)$ \\
Stiffness & $15(100 \%)$ & $15(100 \%)$ \\
Contractures & $6(40 \%)$ & $9(60 \%)$ \\
Diminished muscle bulk & $9(60 \%)$ & $12(80 \%)$ \\
\hline
\end{tabular}

measured using a goniometer and muscle bulk with a tape measure. Each patient reported the presence or absence of stiffness and muscle contractures. The main symptoms for all patients are given in Table 1 .

\section{Treatments}

Group A treatment consisted of a course of traditional physiotherapy sessions with local hyperthermia. Group $B$ received a course of REAC in an attempt to improve their motor skills.

\section{Hyperthermia}

The hyperthermia device ${ }^{25}$ (Easytech, Bari, Italy) is used in the field of endogenous thermotherapy. The device is capable of delivering endogenous heat using electromagnetic fields at $433.92 \mathrm{mHz}$ or delivering exogenous heat using a thermostatically controlled heated water bolus. Increased depth in tissue compared with laser therapy. Treatment consisted of 12, 3-weekly sessions of hyperthermia administered on alternate days. Each treatment session, using a water bolus warmed to $37.5^{\circ} \mathrm{C}$ by $65 \mathrm{~W}$ of power, lasted for 30 minutes.

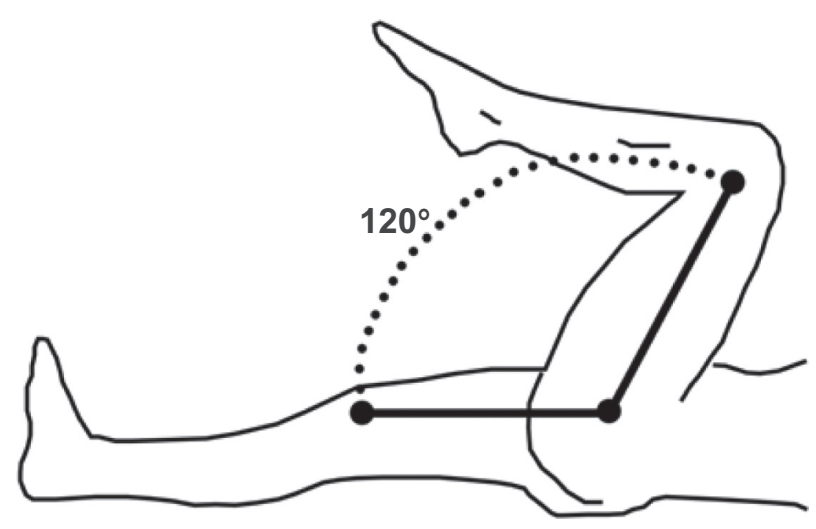

Figure I Range of motion in terms of active flexion of hip: knee flexion. 


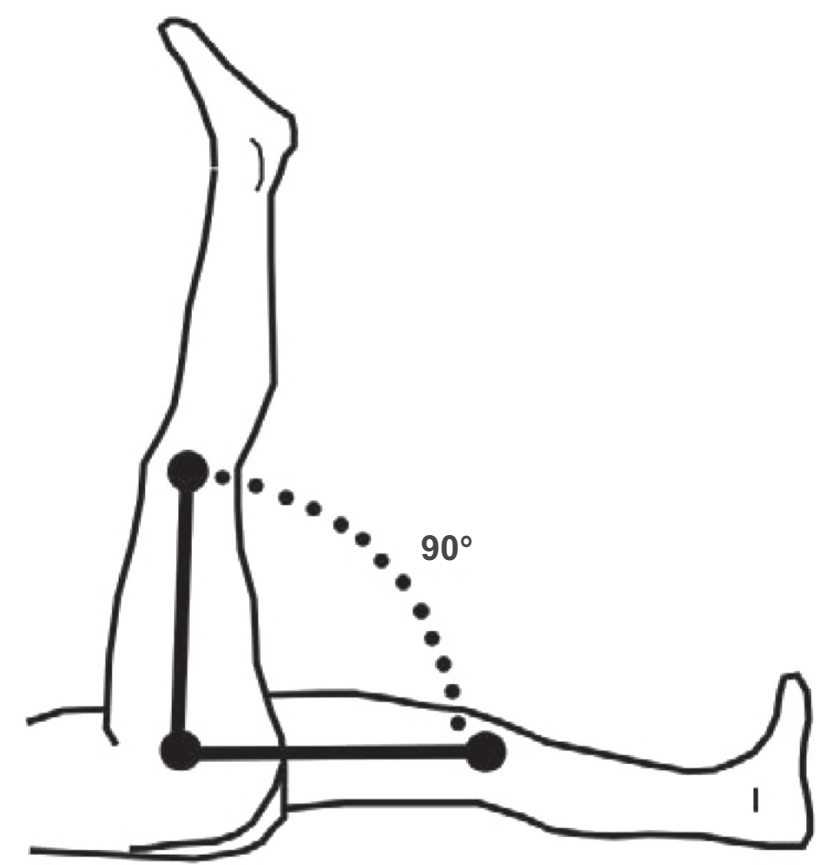

Figure 2 Range of motion in terms of active flexion of hip: knee extension.

\section{Radioelectric asymmetric conveyor}

The REAC is an innovative biostimulation medical device (Convogliatore di Radianza Modulante, Asmed, Italy). ${ }^{26,27}$ REAC therapy has been shown to be efficacious in ameliorating motor behavior abnormalities, ${ }^{28}$ stress-related disorders, depression, anxiety, ${ }^{29-34}$ and bipolar disorders. ${ }^{35}$ It works through a typical range of frequencies of $2.4,5.8$, or $10.5 \mathrm{gHz}$, as selected by the operator for each specific protocol used. A frequency of $10.5 \mathrm{gHz}$ was used for the brain stimulation protocols in this study. The radioelectric parameters were as follows: radiated power, approximately $2 \mathrm{~mW}$; electric field, $\mathrm{E}=0.1 \mathrm{~V} / \mathrm{m}$; magnetic field, $0.23 \mathrm{~mA} / \mathrm{m}$; and specific absorption rate, $7 \mu \mathrm{W} / \mathrm{kg}$. A sequence of seven radiofrequency pulses of $500 \mathrm{msec}$, called neuropsychophysical

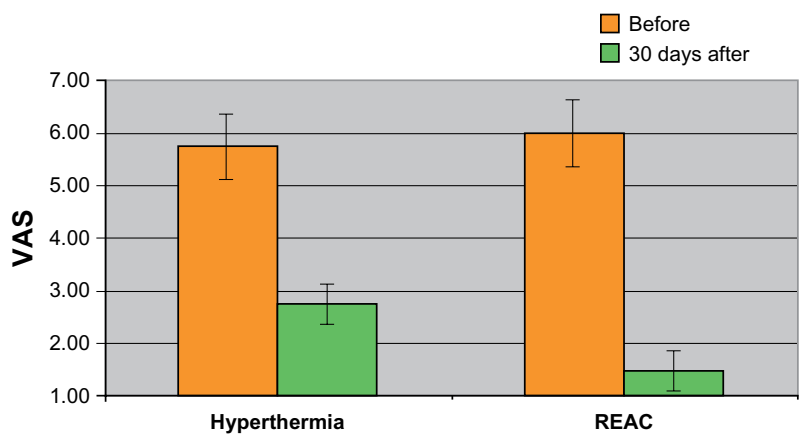

Figure 3 Additional graph for Table 2: mean of the pain variation in VAS scale before and after the two treatments (hyperthermia/REAC).

Abbreviation: REAC, radioelectric asymmetric brain stimulation; VAS, visual analog scale.

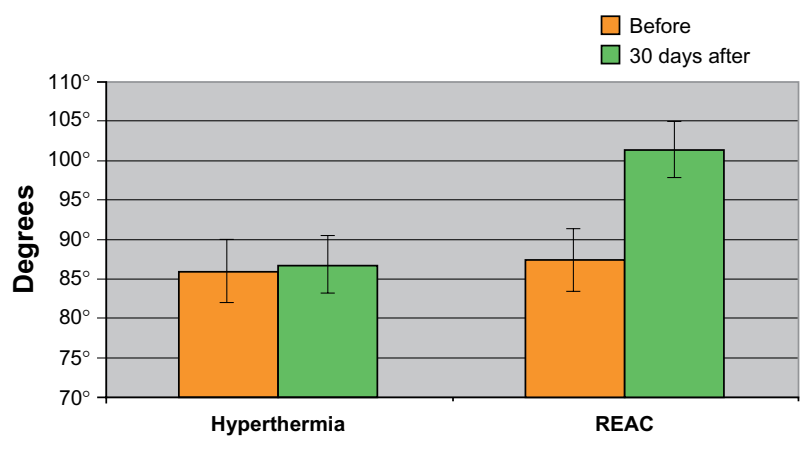

Figure 4 Additional graph for Table 3: mean of the hip-bending angle with the knee flexed before and after the two treatments (hyperthermia/REAC) (normal angle $=120^{\circ}$ ).

Abbreviation: REAC, radioelectric asymmetric brain stimulation.

optimization, was applied by touching the metallic tip of the REAC probe onto seven reflex auricular points. This protocol, consisting of 18 sessions administered on alternate days, is always preceded by a preparatory session, called neuropostural optimization. ${ }^{28}$ This protocol, which consists of a $500 \mathrm{msec}$ single pulse in a specific area of the ear located at the top of the lower third of the scapha, was specifically designed for the reorganization of neuromuscular control.

\section{Statistical analysis}

Statistical analysis was performed using the Wilcoxon signedranks test and Sign-test for comparative groups. We used SPSS Release 13 (SPSS Inc, Chicago, IL) for data analysis.

\section{Results}

The patients in Group A showed a significant decrease in pain and stiffness, but no significant improvement in joint range of motion or muscle bulk. The condition of one patient in Group A worsened, and the pain did not completely disappear in any patient. One month after the end of treatment at T1, visual analog scores ranged from 7 to 1 (mean, 2.73, see Table 2). At T0, the range of active flexion of the hip with

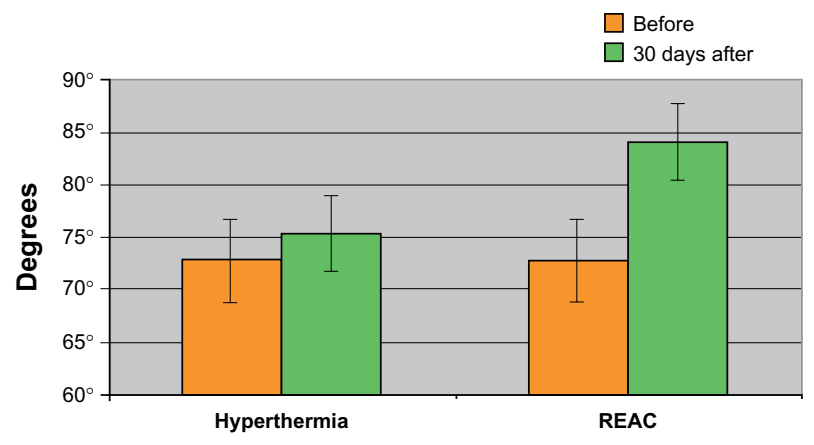

Figure 5 Additional graph for Table 4: mean of the hip-bending angle with the knee extended before and after the two treatments (hyperthermia/REAC) (normal angle $=90^{\circ}$ ).

Abbreviation: REAC, radioelectric asymmetric brain stimulation. 
Table 2 Pain variation before and 30 days after the two treatments

\begin{tabular}{lllll}
\hline VAS & $\begin{array}{l}\text { Group A } \\
\text { (T0) }\end{array}$ & $\begin{array}{l}\text { Group A } \\
\text { (TI) }\end{array}$ & $\begin{array}{l}\text { Group B } \\
\text { (T0) }\end{array}$ & $\begin{array}{l}\text { Group B } \\
\text { (TI) }\end{array}$ \\
\hline 10 & & & & \\
9 & & & $3 \mathrm{Pz}$ & \\
8 & $\mathrm{I} \mathrm{Pz}$ & & $\mathrm{IPz}$ & \\
7 & $2 \mathrm{Pz}$ & $\mathrm{I} \mathrm{Pz}$ & $5 \mathrm{Pz}$ & \\
6 & $6 \mathrm{Pz}$ & & $5 \mathrm{Pz}$ & \\
5 & $4 \mathrm{Pz}$ & & $1 \mathrm{Pz}$ & \\
4 & $2 \mathrm{Pz}$ & $2 \mathrm{Pz}$ & & $\mathrm{I} \mathrm{Pz}$ \\
3 & & $5 \mathrm{Pz}$ & & $6 \mathrm{Pz}$ \\
2 & & $4 \mathrm{Pz}$ & & $7 \mathrm{Pz}$ \\
1 & & $3 \mathrm{Pz}$ & & $1 \mathrm{Pz}$ \\
0 & & & & $1.47^{\circ} \pm 0.74$ \\
\hline
\end{tabular}

Abbreviations: T0, before treatment; TI, 30 days after treatment; VAS, visual analog scale.

Table 3 Active flexion of hip with knee flexed (normal range $120^{\circ}$ ) before and 30 days after the two treatments

\begin{tabular}{lllll}
\hline $\begin{array}{l}\text { Motion } \\
\text { range } \\
\text { (degrees) }\end{array}$ & $\begin{array}{l}\text { Group A } \\
\text { (T0) }\end{array}$ & $\begin{array}{l}\text { Group A } \\
\text { (TI) }\end{array}$ & $\begin{array}{l}\text { Group B } \\
\text { (T0) }\end{array}$ & $\begin{array}{l}\text { Group B } \\
\text { (TI) }\end{array}$ \\
\hline $120^{\circ}$ & & & & $1 \mathrm{Pz}$ \\
$110^{\circ}$ & & & & $4 \mathrm{Pz}$ \\
$10^{\circ}$ & $2 \mathrm{Pz}$ & $2 \mathrm{Pz}$ & $2 \mathrm{Pz}$ & $6 \mathrm{Pz}$ \\
$90^{\circ}$ & $6 \mathrm{Pz}$ & $6 \mathrm{Pz}$ & $8 \mathrm{Pz}$ & $4 \mathrm{Pz}$ \\
$80^{\circ}$ & $6 \mathrm{Pz}$ & $7 \mathrm{Pz}$ & $4 \mathrm{Pz}$ & \\
$70^{\circ}$ & $\mathrm{I} \mathrm{Pz}$ & & $1 \mathrm{Pz}$ & \\
Mean value & $86.00^{\circ} \pm 8.28$ & $87.00^{\circ} \pm 7.24$ & $87.33^{\circ} \pm 9.15$ & $101.33 \pm 7.99$ \\
\hline
\end{tabular}

Abbreviations: T0, before treatment; TI, 30 days after treatment.

Table 4 Active flexion of hip with knee extended (normal range $90^{\circ}$ ) before and 30 days after the two treatments

\begin{tabular}{lllll}
\hline $\begin{array}{l}\text { Motion range } \\
\text { (degrees) }\end{array}$ & $\begin{array}{l}\text { Group A } \\
\text { (T0) }\end{array}$ & $\begin{array}{l}\text { Group A } \\
\text { (TI) }\end{array}$ & $\begin{array}{l}\text { Group B } \\
\text { (T0) }\end{array}$ & $\begin{array}{l}\text { Group B } \\
\text { (TI) }\end{array}$ \\
\hline $90^{\circ}$ & & & & $7 \mathrm{Pz}$ \\
$80^{\circ}$ & $5 \mathrm{Pz}$ & $8 \mathrm{Pz}$ & $7 \mathrm{Pz}$ & $7 \mathrm{Pz}$ \\
$70^{\circ}$ & $9 \mathrm{Pz}$ & $7 \mathrm{Pz}$ & $5 \mathrm{Pz}$ & $\mathrm{I} \mathrm{Pz}$ \\
$60^{\circ}$ & $\mathrm{Pzz}$ & & $3 \mathrm{Pz}$ & \\
Mean value & $73.00^{\circ} \pm 6.11$ & $75.00^{\circ} \pm 5.16$ & $72.67^{\circ} \pm 7.99$ & $84.00^{\circ} \pm 6.32$ \\
\hline
\end{tabular}

Abbreviations: $\mathrm{T} 0$, before treatment; $\mathrm{TI}, 30$ days after treatment. the knee flexed ranged from $80^{\circ}$ to $100^{\circ}$ (mean, $86^{\circ}$ ) and showed no change after 1 month of treatment $\left(80^{\circ}-100^{\circ}\right.$, mean, $86.7^{\circ}$, Table 3 ). Active flexion of the hip with the knee extended ranged from $60^{\circ}$ to $80^{\circ}$ pretreatment at $\mathrm{T} 0$ (mean $72.7^{\circ}$ ), which changed to $70^{\circ}-80^{\circ}$ (mean $75.3^{\circ}$ ) after 1 month of treatment (see Table 4). Patients in Group B experienced a significant decrease in symptoms of pain and stiffness, and significant improvements in range of movement and bulk. No patients worsened during treatment, and pain resolved completely in one patient. The initial visual analog scores at T0 ranged from 4 to 8 (mean 6.0), but improved to 0-3 (mean 1.47) after 1 month of treatment. At baseline in Group B, active flexion of the hip with the knee flexed ranged from $70^{\circ}$ to $100^{\circ}$ (mean $87.3^{\circ}$ ), which improved to $90^{\circ}-120^{\circ}$ (mean $101.3^{\circ}$ ) 1 month after treatment (Table 3). Active flexion of the hip with the knee extended improved from $60^{\circ}$ to $80^{\circ}$ pretreatment (mean $72.7^{\circ}$ ) to $70^{\circ}$ to $90^{\circ}$ (mean $84.0^{\circ}$ ) following treatment. Statistical analysis showed that the change in Group B was statistically significant compared with Group A (Table 5).

The treatments in both groups were painless and noninvasive. The only side effect found was in the REAC group, in which some patients experienced a transient increase in pain during sessions 6-10, although the functional capacity of their hip joints continued to improve over this period.

\section{Discussion}

It is well known that the therapeutic response may be different in different subjects after the same treatment is applied, which may be due in part to a psychogenic behavioral component. ${ }^{36-38}$ This can often be difficult to recognize by both the therapist and the patient. The results of our study show that physiotherapy with local hyperthermia is effective, but less so than treatment with REAC to improve motor skills. Physiotherapy aims to reduce symptoms without addressing the underlying cause, and does little to address the aberrant motor behavior caused by neuropsychophysical responses

Table 5 Statistical analysis using Wilcoxon signed-rank test and sign-test

\begin{tabular}{llll}
\hline & VAS & Active flexion of hip with knee flexed & Active flexion of hip with knee extended \\
\hline Group A & $\mathrm{Z}=-3.15 \mathrm{I}$ & $\mathrm{Z}=-0.577$ & $\mathrm{Z}=-2.577$ \\
& Asymp sig (2-tailed) $=0.002$ & Asymp sig (2-tailed) $=0.564$ & Asymp sig (2-tailed) $=0.046$ \\
& Exact sig (2-tailed) $=0.001$ & Exact sig (2-tailed) $=1.000$ & Exact sig (2-tailed) $=0.125$ \\
Group B & $\mathrm{Z}=-3.427$ & $\mathrm{Z}=-3.520$ & $\mathrm{Z}=-3.690$ \\
& Asymp sig (2-tailed) $=0.00 \mathrm{I}$ & Asymp sig (2-tailed) $=0.000$ & Asymp sig (2-tailed) $=0.000$ \\
& Exact sig (2-tailed) $=0.000$ & Exact sig (2-tailed) $=0.000$ & Exact sig (2-tailed) $=0.000$ \\
\hline
\end{tabular}

Abbreviation: Asymp sig, asymptotic significance; exact sig, exact significance; VAS, visual analog score. 
to environmental stresses. ${ }^{1,2}$ It is likely that the REAC brain stimulation protocol achieves a better response in those areas of the brain responsible for controlling mood and motor behavior, ${ }^{39-43}$ which can be altered at a young age ${ }^{44}$ and predispose to physical manifestations in adults. These aspects are particularly important in the elderly, in whom functional limitation is often associated with or exacerbated by a psychogenic component.

\section{Conclusion}

Treatments in both groups of patients were well tolerated and safe. The values in the tables show the results of the different treatments. We suggest that further investigation is warranted to determine the usefulness of REAC as a supplementary treatment for elderly patients with coxarthrosis.

\section{Acknowledgment}

The authors extend their gratitude to Lucia Aravagli and Stefania Bini of the Rinaldi Fontani Institute for their helpful support.

\section{Disclosure}

Salvatore Rinaldi and Vania Fontani are the inventors of the REAC.

\section{References}

1. McEwen BS. Plasticity of the hippocampus: adaptation to chronic stress and allostatic load. Ann NY Acad Sci. 2001;933:265-277.

2. Huether G, Doering S, Ruger U, Ruther E, Schussler G. Psychological stress and neuronal plasticity. An expanded model of the stress reaction process as the basis for understand central nervous system adaptation processes. Z Psychosom Med Psychoanal. 1996;42(2):107-127. German.

3. McEwen BS. The brain is the central organ of stress and adaptation. Neuroimage. 2009;47(3):911-913.

4. McEwen BS, Gianaros PJ. Central role of the brain in stress and adaptation: links to socioeconomic status, health, and disease. Ann N Y Acad Sci. 2010;1186:190-222.

5. Baik JS, Lang AE. Gait abnormalities in psychogenic movement disorders. Mov Disord. 2007;22(3):395-399.

6. Hallett M. Psychogenic movement disorders: a crisis for neurology. Curr Neurol Neurosci Rep. 2006;6(4):269-271.

7. Hinson VK, Haren WB. Psychogenic movement disorders. Lancet Neurol. 2006;5(8):695-700.

8. Nowak DA, Fink GR. Psychogenic movement disorders: aetiology, phenomenology, neuroanatomical correlates and therapeutic approaches. Neuroimage. 2009;47(3):1015-1025.

9. Thomas M, Jankovic J. Psychogenic movement disorders: diagnosis and management. CNS Drugs. 2004;18(7):437-452.

10. Dekker J, Boot B, van der Woude LH, Bijlsma JW. Pain and disability in osteoarthritis: a review of biobehavioral mechanisms. J Behav Med. 1992;15(2):189-214.

11. Schute A, Neraal A, Wilke A. Psychogenic joint contractures exemplified by somatoform hysteria. Z Orthop Ihre Grenzgeb. 2000; 138(4):369372. German.

12. Szer IS. Musculoskeletal pain syndromes that affect adolescents. Arch Pediatr Adolesc Med. 1996;150(7):740-747.
13. van Baar ME, Dekker J, Lemmens JA, Oostendorp RA, Bijlsma JW. Pain and disability in patients with osteoarthritis of hip or knee: the relationship with articular, kinesiological, and psychological characteristics. $J$ Rheumatol. 1998;25(1):125-133.

14. Wright HP. Psychogenic arthralgia. Ann Rheum Dis. 1947;6(4): 204-207.

15. Zwierzchowski H, Zwierzchowska D. Psychogenic contractures of the joints. Chir Narzadow Ruchu Ortop Pol. 1989;54(1):63-66. Polish.

16. Kvartsakhava ML, Saakadze VP, Tsimakuridze MP, Zurashvili DG, Khachapuridze NA. Health peculiarities among Georgian national ballet dancers. Georgian Med News. 2006;136:121-124. Russian.

17. Steultjens MP, Dekker J, Bijlsma JW. Coping, pain, and disability in osteoarthritis: a longitudinal study. J Rheumatol. 2001;28(5): 1068-1072.

18. Imhof H, Nobauer-Huhmann I, Trattnig S. Coxarthrosis - an update. Radiologe. 2009;49(5):400-409. German.

19. Jurman RD. Stress and the etiology of osteoarthritis. Am J Phys Anthropol. 1977;46(2):353-365.

20. van Beilen M, Griffioen BT, Leenders KL. Coping strategies and IQ in psychogenic movement disorders and paralysis. Mov Disord. 2009;24(6):922-925.

21. Zimerman M, Hummel FC. Non-invasive brain stimulation: enhancing motor and cognitive functions in healthy old subjects. Front Aging Neurosci. 2010;2:149.

22. Hummel FC, Cohen LG. Non-invasive brain stimulation: a new strategy to improve neurorehabilitation after stroke? Lancet Neurol. 2006;5(8):708-712.

23. Hummel F, Celnik P, Giraux P, et al. Effects of non-invasive cortical stimulation on skilled motor function in chronic stroke. Brain. 2005;128(Pt 3):490-499.

24. Fregni F, Pascual-Leone A. Technology insight: noninvasive brain stimulation in neurology - perspectives on the therapeutic potential of rTMS and tDCS. Nat Clin Pract Neurol. 2007;3(7):383-393.

25. Ipertermia in Terapia Fisica [computer program]. Milan, Italy: Edi Ermes; 1998.

26. Rinaldi S, Fontani V, inventors; Rinaldi S, Fontani V, assignees. Radioelectric asymmetric conveyer for therapeutic use. US patent 7,333,8592001.

27. Rinaldi S, Fontani V, inventors; Rinaldi S, Fontani V, assignees. Radioelectric asymmetric conveyer for therapeutic use. US patent EP1301241 (B1). October 11, 2006.

28. Castagna A, Rinaldi S, Fontani V, Mannu P. Radioelectric asymmetric brain stimulation and lingual apex repositioning in patients with atypical deglutition. J Multidiscip Healthc. 2011;4(1):209-213.

29. Rinaldi S, Fontani V, Moretti E, et al. A new approach on stress-related depression and anxiety: neuro-psycho-physical-optimization with radio electric asymmetric conveyer. Indian J Med Res. 2010;132:189-194.

30. Rinaldi S, Fontani V, Aravagli L, Mannu P. Psychometric evaluation of a radio electric auricular treatment for stress related disorders: a double-blinded, placebo-controlled controlled pilot study. Health Qual Life Outcomes. 2010;8(1):31.

31. Rinaldi S, Fontani V, Aravagli L, Margotti ML. Psychological and symptomatic stress-related disorders with radio-electric treatment: psychometric evaluation. Stress and Health. 2009; Published online: January 20, 2010.

32. Mannu P, Rinaldi S, Fontani V, Castagna A, Lotti Margotti M. Radio electric treatment vs es-citalopram in the treatment of panic disorders associated with major depression: an open-label, naturalistic study. Acupunct Electrother Res. 2009;34(3-4):135-149.

33. Collodel G, Moretti E, Fontani V, et al. Effect of emotional stress on sperm quality. Indian J Med Res. 2008;128(3):254-261.

34. Castagna A, Rinaldi S, Fontani V, Aravagli L, Mannu P, Margotti ML. Does osteoarthritis of the knee also have a psychogenic component? Psycho-emotional treatment with a radio-electric device vs intraarticular injection of sodium hyaluronate: an open-label, naturalistic study. Acupunct Electrother Res. 2010;35(1-2):1-16. 
35. Mannu P, Rinaldi S, Fontani V, Castagna A. Long-term treatment of bipolar disorder with a radioelectric asymmetric conveyor. Neuropsychiatr Dis Treat. 2011;7(1):373-379.

36. Sumathipala A, Siribaddana S, Abeysingha MR, et al. Cognitivebehavioural therapy vs structured care for medically unexplained symptoms: randomised controlled trial. Br J Psychiatry. 2008;193(1): 51-59.

37. Smith RC, Dwamena FC. Classification and diagnosis of patients with medically unexplained symptoms. J Gen Intern Med. 2007;22(5): 685-691.

38. Rief W. Analyzing the problems in managing patients with medically unexplained symptoms. J Gen Intern Med. 2007;22(5):704-706.

39. Timmann D, Drepper J, Frings M, et al. The human cerebellum contributes to motor, emotional and cognitive associative learning: a review. Cortex. 2010;46(7):845-857.
40. Sacchetti B, Scelfo B, Strata P. Cerebellum and emotional behavior. Neuroscience. 2009;162(3):756-762.

41. Sagaspe P, Schwartz S, Vuilleumier P. Fear and stop: a role for the amygdala in motor inhibition by emotional signals. Neuroimage. 2011;55(4):1825-1835.

42. Holstege G. The mesopontine rostromedial tegmental nucleus and the emotional motor system: role in basic survival behavior. J Comp Neurol. 2009;513(6):559-565.

43. Caruana F, Jezzini A, Sbriscia-Fioretti B, Rizzolatti G, Gallese V. Emotional and social behaviors elicited by electrical stimulation of the insula in the macaque monkey. Curr Biol. 2011;21(3):195-199.

44. Cairney J, Veldhuizen S, Szatmari P. Motor coordination and emotional-behavioral problems in children. Curr Opin Psychiatry. 2010;23(4):324-329.
Clinical Interventions in Aging

\section{Publish your work in this journal}

Clinical Interventions in Aging is an international, peer-reviewed journal focusing on evidence-based reports on the value or lack thereof of treatments intended to prevent or delay the onset of maladaptive correlates of aging in human beings. This journal is indexed on PubMed Central, MedLine, the American Chemical Society's 'Chemical Abstracts Ser-

\section{Dovepress}

vice' (CAS), Scopus and the Elsevier Bibliographic databases. The manuscript management system is completely online and includes a very quick and fair peer-review system, which is all easy to use. Visit $\mathrm{http}: / / \mathrm{www}$.dovepress.com/testimonials.php to read real quotes from published authors.

Submit your manuscript here: http://www.dovepress.com/clinical-interventions-in-aging-journal 